Pacific Journal of Mathematics

ASYMMETRY OF A PLANE CONVEX SET WITH RESPECT TO
ITS CENTROID 


\section{ASYMMETRY OF A PLANE CONVEX SET WITH \\ RESPECT TO ITS CENTROID}

\section{B. M. STEWART}

A. S. Besicovitch [1] proved that every bounded plane convex set $K$ has a central subset of area at least $2 m(K) / 3$ where $m(K)$ denotes the area of $K$. His method is to construct a semi-regular hexagon of center $N$ whose vertices belong to the boundary of $K$.

Ellen F. Buck and R. C. Buck [2] showed that for every $K$ there exists at least one point $X$, called a six-partite point, such that there are three straight lines through $X$ dividing $K$ into six subsets each of area $m(K) / 6$. H. G. Eggleston [3] showed that any six-partite point of $K$ is the center of a semi-regular hexagon of area $2 m(K) / 3$ contained in $K$.

I. Fáry and L. Rédei [4] and S. Stein [5] defined for each point $P$ the subset $S(P)$ of $K$ determined by the intersection of $K$ with its radial reflection in $P$ and considered the function $f(P)=m(S(P)) / m(K)$. By use of the Brunn-Minkowski theorem these authors showed that if $a$ is a real number, then the set of points at which $f(P) \geqq a$ is convex; and the maximum $f^{*}$ of $f(P)$ is attained at a single point. (Moreover, these results apply to an $n$-dimensional bounded convex set in $n$-dimensional Euclidean space.) Note that these conclusions may be false if the set $K$ is not convex: for example, consider an $L$-shaped region formed by deleting one quarter of a square.

The results of Besicovitch and Eggleston imply $f(N) \geqq 2 / 3$ and $f(X)$ $\geqq 2 / 3$, hence $f^{*} \geqq 2 / 3$.

We obtain the following theorem.

THEOREM. If $G$ is the centroid of $K$, then $f(G) \geqq 2 / 3$.

To see that this result is not included in the theorems previously mentioned, consider the isosceles trapezoid with vertices $(-4,0),(4,0)$, $(2,2),(-2,2)$. For this example there is only one point $N:(0,1)$ and only one point $X:(0,4-4 \sqrt{.6})$ and the closure of these points does not include $G:(0,8 / 9)$.

Proof of the theorem. If $K$ has central symmetry, then $f(G)=1$. In any case $S(G)$ has central symmetry about $G$; hence if $K$ does not have central symmetry, the part $M$ of $K$ outside $S(G)$ has $G$ at its centroid. Then as in Figure 1 let $T$ be any maximal connected subset of $M$ with

Received October 10, 1957. 
$A$ and $B$ as terminal points of the boundary curve common to $K$ and $T$. Let $P^{\prime}$ denote the reflection of a point $P$ in $G$. Note that the congruent triangles $A G B$ and $A^{\prime} G B^{\prime}$ are contained in $S(G)$.

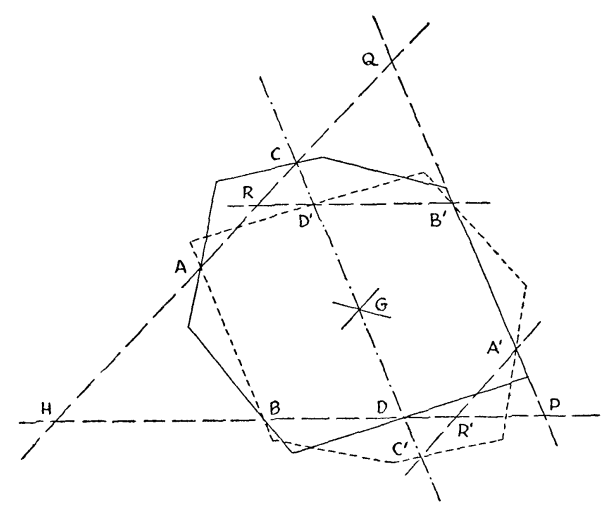

Fig. 1.

If for every $T$ the area $m(T)$ is less than or equal to the area $\triangle$ of the corresponding triangle $A G B$, then $m(S(G)) \geqq 2 m(M)$. Since

$$
\begin{aligned}
m(K)=m(M) & +m(S(G)) \\
& \leqq 3 m(S(G)) / 2,
\end{aligned}
$$

it follows that $f(G) \geqq 2 / 3$.

In the contrary case, if we assume for any $T$ that $m(T)>\Delta$, we can arrive at a contradiction of the fact that $G$ is the centroid of $M$.

Let line $L$ through $G$ parallel to $A B$ cut the boundary of $K$ in points $C$ and $D$. To fix ideas suppose in length $C G>G D$. Let lines $B D$ and $A C$ meet at $H$ and intersect line $A^{\prime} B^{\prime}$ in $P$ and $Q$, respectively. Let $A C$ and $B^{\prime} D^{\prime}$ meet at $R$; then $B D$ and $A^{\prime} C^{\prime}$ meet at $R^{\prime}$; and $R$ is on the side of $L$ toward $T$.

Considerations of convexity imply that on the side of $L$ away from $T$ the maximum possible moment of $M$ with respect to $L$ is $u+w_{2}$ where $u$ is the moment of triangle $R^{\prime} A^{\prime} P$ and $w_{2}$ is the moment of trapezoid $C Q B^{\prime} D^{\prime}$. On the other side the minimum possible moment of $M$ with respect to $L$ is $w_{1}+v$ where $w_{1}$ is the moment of triangle $R C D^{\prime}$ and $v$ is the moment of a trapezoid of area $m(T)$ inscribed in triangie $A B H$ and having $A B$ as one base.

We will show that if $m(T)>\Delta$, then $w_{1}+v>u+w_{2}$, in contradiction to $G$ being the centroid of $M$. It will suffice to show $v>u+w$ where $w=w_{2}-w_{1}$ is the moment of triangle $R Q B^{\prime}$.

Let $a=A B$, let $d$ be the distance from $G$ to $A B$ and let $h$ be the distance from $H$ to $A B$. Let $a_{1}=A^{\prime} P$ and $a_{2}=Q B^{\prime}$. From similar triangles $\left(a_{1}+a_{2}+a\right) / a=(2 d+h) / h$, so that $a_{1}+a_{2}=2 a d / h$. The combined moments of triangles $R^{\prime} A^{\prime} P$ and $R Q B^{\prime}$ are equivalent to those of a single triangle of base $a_{1}+a_{2}$ and altitude $d$ with centroid at a distance $2 d / 3$ from $L$, hence $u+w=2 a d^{3} / 3 h$.

Let $c$ be the altitude of a trapezoid $Z$ of area $\triangle$ inscribed in triangle $A B H$ and having $A B$ as one base. A direct computation shows the moment $v^{\prime}$ of $Z$ with respect to $L$ to be

$$
v^{\prime}=\frac{a d}{2}\left(d+\frac{c(3 h-2 c)}{3(2 h-c)}\right) .
$$

Since $m(T)>\Delta$ implies $v>v^{\prime}$ the inequality $v>u+w$ will hold if 
$v^{\prime}>u+w$. Since $m(T)>\Delta$ also implies $h>d>c$, the inequality $v^{\prime}>u+w$ reduces to

$$
\left(6 h d-3 c d+3 c h-2 c^{2}\right) h>4 d^{2}(2 h-c) .
$$

Comparison of the areas of $Z$ and triangle $A B G$ shows $c^{2}=2 c h-h d$. Then the previous inequality may be rearranged and factored to obtain the equivalent inequality

$$
8 h d(h-d)>c(h+4 d)(h-d)
$$

whose truth follows readily from $h>d>c$.

The case that length $C G=G D$ may be treated in the same manner (even if $B D$ and $A C$ are parallel). This completes the proof of the theorem.

We do not see how to extend the theorem about $f(G)$ to higher dimensions. Possibly the lower limit for $f(G)$ for the general bounded convex set is the same as $f(G)$ for a simplex of corresponding dimension. The value of the latter is given in [4] (but incorrectly given in Theorem 6 of [5], an error for which Professor Stein wishes this note to serve in lieu of a formal corrigendum).

Note that for as simple an example as a trapezoid $f^{*}>f(G)$. Some necessary conditions for determining $P$ such that $f(P)=f^{*}$ have been given in [6].

\section{REFERENCES}

1. A. S. Besicovitch, Measure of asymmetry of convex curves, J. London Math. Soc. 23 (1948), 237-240.

2. Ellen F. Buck and R. C Buck, Equipartition of convex sets, Math. Mag. 22 (1949), 195-198.

3. H. G. Eggleston, Some properties of triangles as extremal curves, J. London Math Soc. 28 (1953). 32-36.

4. I. Fáry and L. Rédei, Der zentralsymmetrische Kern und die zentralsymmetrische Hülle von konvexen Körpern, Math. Ann. 122 (1950), 205-220.

5. S. Stein, The symmetry function in a convex body, Pacific J. Math. 6 (1956), 145-147.

6. B. M. Stewart, The two-area covering problem, Amer. Math. Monthly 50 (1951), 394403.

Michigan State University 



\section{PACIFIC JOURNAL OF MATHEMATICS}

\section{EDITORS}

\section{H. L. Royden}

Stanford University

Stanford, California

\section{R. A. Beaumont}

University of Washington

Seattle 5 , Washington

\author{
A. L. Whiteman
}

University of Southern California

Los Angeles 7, California

E. G. Straus

University of California

Los Angeles 24, California

\section{ASSOCIATE EDITORS}
E. F. BECKENBACH
A. HORN
L. NACHBIN
G. SZEKERES
C. E. BURGESS
V. GANAPATHY IYER
I. NIVEN
F. WOLF
M. HALL
R. D. JAMES
T. G. OSTROM
E. HEWITT
M. S. KNEBELMAN
M. M. SCHIFFER
K. YOSIDA

\section{SUPPORTING INSTITUTIONS}

\author{
UNIVERSITY OF BRITISH COLUMBIA \\ CALIFORNIA INSTITUTE OF TECHNOLOGY \\ UNIVERSITY OF CALIFORNIA \\ MONTANA STATE UNIVERSITY \\ UNIVERSITY OF NEVADA \\ OREGON STATE COLLEGE \\ UNIVERSITY OF OREGON \\ UNIVERSITY OF SOUTHERN CALIFORNIA
}

\author{
STANFORD UNIVERSITY \\ UNIVERSITY OF UTAH \\ WASHINGTON STATE COLLEGE \\ UNIVERSITY OF WASHINGTON \\ * * * * \\ AMERICAN MATHEMATICAL SOCIETY \\ CALIFORNIA RESEARCH CORPORATION \\ HUGHES AIRCRAFT COMPANY \\ THE RAMO-WOOLDRIDGE CORPORATION
}

Mathematical papers intended for publication in the Pacific Journal of Mathematics should be typewritten (double spaced), and the author should keep a complete copy. Manuscripts may be sent to any of the editors. All other communications to the editors should be addressed to the managing editor, E. G. Straus at the University of California, Los Angeles 24, California.

50 reprints per author of each article are furnished free of charge; additional copies may be obtained at cost in multiples of 50 .

The Pacific Journal of Mathematics is published quarterly, in March, June, September, and December. The price per volume (4 numbers) is $\$ 12.00$; single issues, $\$ 3.50$. Back numbers are available. Special price to individual faculty members of supporting institutions and to individual members of the American Mathematical Society: $\$ 4.00$ per volume; single issues, $\$ 1.25$.

Subscriptions, orders for back numbers, and changes of address should be sent to Pacific Journal of Mathematics, 2120 Oxford Street, Berkeley 4, California.

Printed at Kokusai Bunken Insatsusha (International Academic Printing Co., I.td.), No. 10, 1-chome, Fujimi-cho, Chiyoda-ku, Tokyo, Japan.

PUBLISHED BY PACIFIC JOURNAL OF MATHEMATICS, A NON-PROFIT CORPORATION

The Supporting Institutions listed above contribute to the cost of publication of this Journal, but they are not owners or publishers and have no responsibility for its content or policies. 


\section{Pacific Journal of Mathematics}

\section{Vol. 8, No. 2 \\ April, 1958}

John Herbert Barrett, Second order complex differential equations with a real independent variable ............................ 187

Avner Friedman, Remarks on the maximum principle for parabolic equations and its applications ......................... 201

Richard Robinson Goldberg, An inversion of the Stieltjes transform ....... 213

Olavi Hellman, On the periodicity of the solution of a certain nonlinear integral equation .................................. 219

Gilbert Helmberg, A theorem on equidistribution on compact groups...... 227

Lloyd Kenneth Jackson, Subfunctions and the Dirichlet problem ......... 243

Naoki Kimura, The structure of idempotent semigroups. I ............ 257

Stephen Kulik, A method of approximating the complex roots of equations........................................ 277

Ancel Clyde Mewborn, A note on a paper of L. Guttman.............. 283

Zeev Nehari, On the principal frequency of a membrane ............ 285

G. Pólya and I. J. Schoenberg, Remarks on de la Vallée Poussin means and convex conformal maps of the circle ...................... 295

B. M. Stewart, Asymmetry of a plane convex set with respect to its centroid .......................................... 335

Hans F. Weinberger, Lower bounds for higher eigenvalues by finite difference methods

Edwin Weiss and Neal Zierler, Locally compact division rings ......... 369

Bertram Yood, Homomorphisms on normed algebras ................. 373 